[0212-7199(2001) 18: 2; pp 86-87] ANALES DE MEDICINA INTERN Copyright $\odot 2001$ ARAN EDICIONES, S.A.

AN. MED. INTERNA (Madrid) Vol. 18, N. $^{\circ} 2$, pp. $86-87,2001$

\title{
Tiroiditis de Hashimoto y síndrome de Sjögren. ¿Asociación o síndrome múltiple autoinmune?
}

\author{
L. SIERRA SANTOS, A. SENDINO REVUELTA, R. PACHECO CUADROS, \\ G. APARICIO JABALQUINTO, F. J. BARBADO HERNÁNDEZ
}

Servicio de Medicina Interna. Hospital la Paz. Universidad Autónoma. Madrid

\begin{abstract}
HASHIMOTO'S THYROIDITIS AND SJÖGREN'S SYNDROME. ASSOCIATION OR MULTIPLE AUTOIMMUNE SYNDROME?
\end{abstract}

\section{RESUMEN}

Se describe un caso de tiroiditis de Hashimoto $(\mathrm{TH})$ asociado a síndrome de Sjögren (SS) incompleto. Ambas enfermedades inmunológicas no sólo se encuentran asociadas como un hallazgo casual, sino que existen datos en la literatura que implican a mecanismos etiopatogénicos comunes. Publicaciones previas manifiestan que la disfunción tiroidea autoinmune está frecuentemente asociada al SS primario y debería ser investigada, clínica y analíticamente, en todos estos pacientes.

\begin{abstract}
A case of Hashimoto's thyroiditis associated with incomplete Sjö gren's syndrome is revised. Both immune disorders are together not just as a casual event, but literature says that common mechanisms could have something to be. Previous publications express that autoimmune thyroid dysfunction is frecuently associated with primary Sjögren's syndrome and should be sought clinically and by laboratory test in all these patients.
\end{abstract}

PALABRAS CLAVE: Síndrome de Sjögren. Tiroiditis de Hashimoto. Enfermedad autoinmune.
KEY WORDS: Sjögren's sindrome. Hashimoto's thyroiditis. Autoimmu ne disease.

Sierra Santos L, Sendino Revuelta A, Pacheco Cuadros R, Aparicio Jabalquinto G, Barbado Hernández FJ. Tiroiditis de Hashimoto y síndro me de Sjögren. ¿Asociación o síndrome múltiple autoinmune? An Med Interna (Madrid) 2001; 18: 86-87

\section{INTRODUCCIÓN}

Cuando los síntomas y signos correspondientes a varias enfermedades se asocian, al médico clínico se le ofrece el reto de discernir si es el azar el que hace que varias patologías confluyan en un mismo paciente o existe un común origen etiopatogénico responsable de estas asociaciones.

La tiroiditis de Hashimoto (TH) es una enfermedad organo-específica y autoinmune; suele presentar hipofunción tiroidea y bocio, y frecuentemente se asocia a otras enfermedades autoinmunes.

Se presenta el caso de un paciente en el que se asocia una TH con rasgos clínicos de síndrome de Sjögren (SS).

\section{CASO APORTADO}

Varón de 41 años de edad con antecedentes personales de hipercolesterolemia desde hace 2 años; ingeniero en una central nuclear, sin exposición radiactiva, sin antecedentes familiares de interés, que consulta porque seis meses antes comenzó a sentir hormigueos en el hombro y brazo izquierdos, irradiados al otro hombro y sensación de frialdad, cefalea occipital y contractura cervical. Un mes después tuvo molestias en el cuello con el roce de la camisa y en los movimientos de rotación, con hinchazón en hemifacies derecha y región mandibular; posteriormente se añadió astenia y tumefacción parotídea, sin supuración del orificio de drenaje salival, con edema generalizado, claudicación mandibular y sequedad bucal, ronquidos intensos con pausas de apnea ocasionales. En la exploración física destacaba ligero edema palpebral, con hipertrofia parotídea bilateral, de predominio derecho; edema en el cuello, con desaparición de la fosita interclavicular y una adenopatía submandibular derecha de 1 $\mathrm{cm}$, blanda y no adherida a planos profundos.

Parámetros analíticos destacables: colesterol total $363 \mathrm{mg} / \mathrm{dl}$, HDL-colesterol $39 \mathrm{mg} / \mathrm{dl}$, triglicéridos $239 \mathrm{mg} / \mathrm{dl}$, CPK $592 \mathrm{U} / \mathrm{l}$ (fracción MB 23), GPT 52 U/1, LDH 518 U/l. La serología de parotiditis fue positiva para IgG y negativa para IgM; Epstein-Barr, VIH, HTLV I, hepatitis B y C, negativos. Factor reumatoide negativo, anticuerpos antinucleares $1 / 40$ y anticuerpo SSB negativo. Función tiroidea: T4 libre < 0,01 nmol/l y TSH $87 \mathrm{mU} / \mathrm{l}$. ACTH $44 \mathrm{pg} / \mathrm{ml}$, cortisol basal 18,6 mcg/dl. Anticuerpos antitiroglobulina $799 \mathrm{U} / \mathrm{ml}$ (valores normales: 0-70) y anticuerpos antiperoxidasa $509 \mathrm{U} / \mathrm{ml}$ (valores normales: 1,6-70).

Trabajo aceptado: 27 Mayo de 1999

Correspondencia: L. Sierra Santos. C/ Maestro Barbieri, 11 Bajo D. Alcobendas (Madrid), 
La radiografía de tórax, la ecografía abdominal y el electrocardiograma fueron normales. Gammagrafía tiroidea: mínimo bocio difuso con alteraciones sugestivas de tiroiditis. Ecografía tiroidea: tiroides hipoecoico de forma difusa. Punción-aspiración con aguja fina: tiroiditis linfocitaria. Ecografía de las glándulas salivales: aumento difuso de ambas parótidas y submaxilares, especialmente acentuado en la parótida derecha. Biopsia de glándula salival menor: agregados de linfocitos y macrófagos que reemplazan el epitelio glandular con islotes de células mioepiteliales, compatibles con SS. Electromiograma: mínimos datos de afectación miopática leve en músculos proximales, sin aspecto inflamatorio. Test de Schirmer y Rosa de Bengala: negativos.

Tratado con medidas higiénicas dirigidas a paliar la sequedad bucal y tiroxina, actualmente el paciente se encuentra asintomático; su nivel de colesterol, así como las enzimas musculares se han normalizado.

\section{DISCUSIÓN}

El caso presentado asocia un hipotiroidismo por TH y síntomas orales de SS, con evidencia de afectación de glándula salival menor, sin síntomas oculares ni alteraciones analíticas autoinmunes. Es, por tanto, un SS incompleto, de acuerdo a los criterios europeos (2-4).

La prevalencia de enfermedad tiroidea autoinmune y disfunción tiroidea, en general, es alta en pacientes con SS (1). Algunos autores han señalado que la existencia de SS en el contexto de una enfermedad tiroidea no es un acontecimiento casual, como indica su tasa de incidencia de hasta el $37 \%$ en alguna serie, en la que aparecería sobre todo en disfunciones tiroideas que incluyen un cuadro clínico manifiesto y completo (5). En otra serie propuesta para estudiar la afectación de glándulas salivales en 19 casos de tiroiditis autoin- munes, 11 mostraron varios grados de afectación en la biopsia de glándula salival de labio inferior, en la escintigrafía de parótida y en la sialometría (6). De estos once, cumplían criterios de SS seis.

Estas observaciones permiten invocar mecanismos operativos comunes en el desarrollo de la enfermedad inmune tiroidea y salival (5-7), como resultado de un terreno genéticamente predispuesto. Esto viene corroborado por la frecuencia de agrupaciones HLA DRW3 y HLA B8 en el SS, hipotiroidismo primario, la enfermedad de Basedow y la TH $(5,7)$. Esta asociación ha sido también englobada dentro del síndro me autoinmune múltiple (7-11). Por eso, es necesario investigar dicho síndrome en pacientes con enfermedad tiroidea y una historia familiar de enfermedades autoinmunes (7).

Los problemas clínicos e inmunológicos que presentan los pacientes con SS y tiroiditis crónica son idénticos a los encontrados en los pacientes con SS únicamente. Esto indica que estas dos patologías son independientes y que la enfermedad tiroidea no es una manifestación extraglandular del SS (12).

Se ha descrito recientemente la asociación del VIH y el VHC (13-15). La presencia de este último se expresa habitualmente con transaminasas elevadas (3). La alta prevalencia de infección viral por hepatitis $\mathrm{C}$ ha sido comunicada en el SS y en alteraciones tiroideas, pero su relación exacta aún no ha sido demostrada (13).

En pacientes como el nuestro, son necesarios el seguimiento por la posibilidad de aparición de nuevas complicaciones autoinmunes y la vigilancia del desarrollo de un linfoma B de bajo grado tipo MALT (tejido linfoide asociado a mucosas), dado que las células B intraepiteliales probablemente sean las promotoras de estos procesos autoinmunes y -en caso de evolución clonal e inmortalización- actuarían de agente en el desarrollo tumoral $(16,17)$.

\section{Bibliografía}

1. Pérez B, Kraus A, López G, et al. Autoimmune thyroid disease in primary Sjögren's syndrome. Am J Med 1995; 99: 480-484.

2. Arranz JA, Pérez A, Zea A, Álvarez de Mon M. Síndrome de Sjögren. Medicine (IDEPSA) 1997; 54: 2437-2445.

3. Vitali C, Bombardieri S, Moutsopoulos HM, et al. Preliminary criteria for the classification of Sjögren's syndrome. Results of an EEC prospective concerted action. Arthritis Rheum 1993; 36: 340-347.

4. Coll J. Diagnóstico del Síndrome de Sjögren: concepto clínico vigente. An Med Interna (Madrid) 1994; 11: 419-421.

5. Kolsi R, Abid M, Rebai T, et al. Gougerot-Sjögren syndrome associated with dysthyroidism. Rev Rhum Mal Osteartic 1990; 57: 805-808.

6. Warfvinge G, Larson A, Henricsson V, et al. Salivary gland involvement in autoimmune thyroiditis, with special reference to the degree of association with Sjögren's syndrome. Oral Surg Oral Med Oral Pathol Oral Radiol 1992; 74: 288-293.

7. Bouchou K, Andre M, Cathebras P, et al. Thyroid disease and multiple autoimmune syndromes clinical and immunogenetic aspects apropos of 11 cases. Rev Med Interne 1995; 16: 283-287.

8. Gaches F, Sauvage P, Vidal E, et al. Multiple autoimmune syndrome. Rev Med Interne 1993; 14: 177-178.

9. Horita M, Takahashi N, Seike M, et al. A case of primary biliary cirrhosis associated with Hashimoto's thyroiditis, scleroderma and Sjögren's syndrome. Intern Med 1992; 31: 418-421.
10. Kobayashi T, Naka W, Harada T, Nishikawa T. Association of the acral type of pustular psoriasis, Sjögren's syndrome, systemic lupus erythematosus, and Hashimoto's thyroiditis. J Dermatol 1995; 22: 125128.

11. Fain O, Rainfray M, Callard P, et al. Dermatopolymyositis, GougerotSjögren's syndrome, Hashimoto's thyroiditis and glomerulopathy. Nephrologie 1990; 11: 223-225.

12. Ichikawa Y, Fukuda R. Clinical and pathological feautures of Sjögren's syndrome associated with autoimmune thyroid diseases. [Abstract] Nippon Rinsho 1995; 53: 2545-2550.

13. Opolon P, Lunel F. Extrahepatic manifestations related to hepatitis C virus. Pathol Biol Paris 1995; 43: 709-715.

14. Coll J, Palazon J, Yazbeck H, et al. Antibodies to human immunodeficiency virus (HIV-1) in autoimmune diseases: primary Sjögren's syndrome, systemic lupus erythematosus, rheumatoid arthritis and autoimmune thyroid diseases. Clin Rheumatol 1995; 14: 451-457.

15. Lunel F. Hepatitis $\mathrm{C}$ and immunologic anomalies. Gastroenterol Clin Biol 1994; 18: 829-838.

16. Tiemann M, Asbeck R, Wacker HH. Clonal B-cell reaction in Sjögren disease and Hashimoto autoimmune thyroiditis. Pathologe 1996; 17: 289-295.

17. Ko GT, Chow CC, Yeung VT, et al. Hashimoto's thyroiditis, Sjögren's syndrome and orbital lymphoma. Postgrad Med J 1994; 70: 448-451. 